\title{
Performance and Mechanism of a Multi-Functional Superplasticizer for Concrete
}

\author{
Qianping Ran ${ }^{1,2}$, Changwen Miao ${ }^{2}$, Jiaping $\mathrm{Liu}^{2}$, Shishan $\mathrm{Wu}^{1}$ and Jian Shen ${ }^{1, *}$ \\ ${ }^{1}$ School of Chemistry and Chemical Engineering, Nanjing University, Nanjing 210093, P. R. China \\ ${ }^{2}$ Jiangsu Institute of Building Science Co. LTD, Nanjing 210008, P. R. China
}

\begin{abstract}
Shrinkage reducing admixtures (SRA) have been used for several years to reduce the shrinkage of concrete. However, because their prices are very expensive and their dosages are very large, it is not economical for their practical application. Another problem of SRA is the degradation of compressive strength of concrete with SRA. In order to solve the two problems, a new polycarboxylate based superplasticizer with shrinkage reducing function was developed and its mechanism was investigated. According to experimental results, the admixture named JM-PCA (IV) reduces shrinkage of concrete effectively and reduces water content effectively. JM-PCA (IV) at a dosage of $0.25 \%$ decreases the shrinkage of concrete by about 40 to 55 percent at 28 days and 60 days when compared with sulfonated naphthalene formaldehyde condensate superplasticizer at a dosage $0.74 \%$. The possible reason is that a shrinkage reducing component (SRC) and long ethylene oxides(EO) side chain were introduced into the molecular structure. The adsorption-reduction of interface tension is thought to be its main action mechanism of the reduction of shrinkage of JM-PCA (IV). [doi:10.2320/matertrans.47.1599]
\end{abstract}

(Received March 8, 2006; Accepted April 19, 2006; Published June 15, 2006)

Keywords: multi-functional superplasticizer shrinkage mechanism

\section{Introduction}

Concrete is a vital component of our infrastructure and society, from roads to buildings. Its durability is essential in preserving resources and maintaining a sound construction system. In order to meets its intended design purpose and performs acceptably throughout its intended service life, it is required to develop effective methodology for the mitigation of cracks. The cracking can be due to a variety of causes including thermal gradients, moisture gradients, and attack by the external or internal environment (sulfate attack, alkalisilica reaction, etc.). ${ }^{1)}$ But one of the most important causes of cracking in concrete are due to volumetric changes resulted from shrinkage, for example drying shrinkage in general concrete and autogenous shrinkage in high strength concrete. To counteract drying shrinkage, several methods are available to limit shrinkage: (1) expanding and nonshrinking cements, ${ }^{2)}$ (2) surface treatments, ${ }^{3)}$ (3) shrinkage reducing admixtures (SRA), ${ }^{4)}(4)$ expansive admixtures ${ }^{5)}$ and combined usage of SRA and expansive agent. ${ }^{6}$ )

Usually, expansive cement or expansive agent produces expansion by formation of ettringite. The production of ettringite occurs only after a certain period and it is not effective to control early (age) cracking. On the other hand, Commercial products of SRA, which lower surface tension of pore solution, can reduce plastic shrinkage, ${ }^{7)}$ autogenous shrinkage, ${ }^{1)}$ and especially drying shrinkage. ${ }^{4)}$ However, the dosage is very large around $2 \%$ by mass of cement and it is not economical. Another problem is the degradation of compressive strength of concrete with SRA. SRA has no water reduction capability, so it requires to be combined with superplasticizers in practical application. Additionally equipment to supply SRA is needed to be installed in concrete plants.

In order to meet such various requirements, a new shrinkage-reducing superplasticizer is proposed. Sugiyama and Nakanishi, et al., ${ }^{8,9)}$ found that such copolymers can reduce drying shrinkage and still keep the performance of superplasticizer as well by introducing a drying shrinkage reducing component into the molecular structure of maleic anhydride-allyl ether copolymer. But such copolymers have not enough water-reducing properties and desirable shrinkage-reducing effects; there is much space for improvement.

In this paper, the new kind of multifunctional superplasticizer JM-PCA (IV) with a high water-reduction performance and a good shrinkage reduction effect will be reported. In addition, fundamental studies on the influence of multifunctional superplasticizer on settlement shrinkage, autogenous shrinkage, drying shrinkage and also its mechanism will be discussed.

\section{Experimental}

\subsection{Materials and mix proportions}

The materials used in experiments are summarized in Table 1. Portland cement was used for the tests, The cement has a Blaine fineness of $368 \mathrm{~m}^{2} / \mathrm{kg}$, Might 100 is a sulfonated naphthalene formaldehyde condensate superplasticizer, provided by Kao Cor., Shanghai. JM-SRA, a shrinkage-reducing admixture produced by Jiangsu Bote New Materials, China, and can reduces the drying shrinkage of concrete. JM-PCA (IV), developed by our research group, is a multifunctional

Table 1 Materials.

\begin{tabular}{ll}
\hline Cement (C) & $\begin{array}{l}\text { Normal portland cement density }=3.15 \mathrm{~g} / \mathrm{cm}^{3} \\
\text { surface area }=368 \mathrm{~m}^{2} / \mathrm{kg}\end{array}$ \\
\hline Fly ash (FA) & density $=2.20 \mathrm{~g} / \mathrm{cm}^{3}$ \\
\hline Water & fresh clean tap water \\
\hline Fine aggregate $(\mathrm{S})$ & Crushed sand density $=2.61 \mathrm{~g} / \mathrm{cm}^{3}$ \\
\hline Coarse aggregate $(\mathrm{G})$ & Crushed hard sandstone density $=2.84 \mathrm{~g} / \mathrm{cm}^{3}$ \\
\hline & JM-PCA (IV): multi-functional superplasticizer \\
& $\begin{array}{l}\text { Might100: polynaphthalene } \\
\text { Organic admixtures }\end{array}$ \\
& sulfonate salt superplasticizer \\
& JM-SRA: a shrinkage-reducing admixture \\
\hline
\end{tabular}




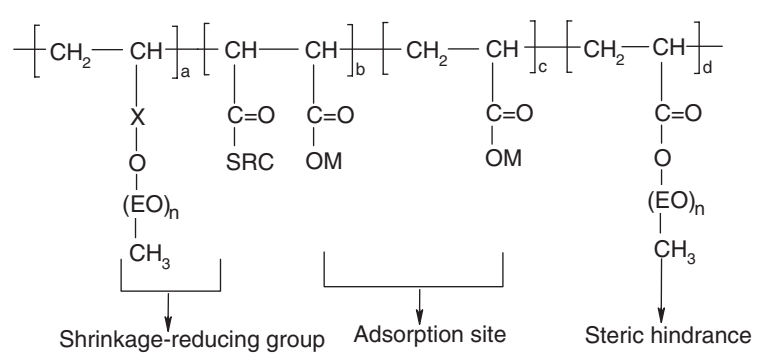

Fig. 1 Chemical structure of JM-PCA (IV) multifunctional superplasticizer.

Table 2 Mixture proportions of concrete for measuring autogenous shrinkage and drying shrinkage.

\begin{tabular}{cccccccc}
\hline \multirow{2}{*}{ Type of admixture } & $\begin{array}{c}\text { Target } \\
\text { slump }(\mathrm{cm})\end{array}$ & \multicolumn{5}{c}{ Unit amount $\left(\mathrm{kg} / \mathrm{m}^{3}\right)$} \\
\cline { 3 - 7 } & & $\mathrm{W}$ & $\mathrm{FA}$ & $\mathrm{S}$ & $\mathrm{G}$ \\
\hline $\begin{array}{c}\text { JM-PCA (IV) } \\
\text { Might100 }\end{array}$ & $18-20$ & 150 & 399.5 & 70.5 & 734 & 1140 \\
Might100+JM-SRA & & & & & & \\
\hline
\end{tabular}

superplasticizer with a high water-reduction performance and a good shrinkage reduction effect. Estimated molecular structure of JM-PCA (IV) is show in Fig. 1. The shrinkage reduction component (SRC) used for JM-PCA (IV) is diethylene glycol dipropylene glycol monobutyl ether.

Table 2 describe the mix proportions for measuring shrinkage of concrete.

\subsection{Tests of fresh and hardened concrete}

The concrete specimens were prepared and stored according to Chinse standard GB8076-1997. The properties of concrete were evaluated by following methods.

Concrete slump, air content, water-reduction rate and setting time were measured in accordance with GB8076-1997.

Compressive strengths were tested at $24 \mathrm{~h}, 3,7,28$ and 60 days according to GB/T50081-2002 (each result is an average of six measurements).

\subsection{Shrinkage measurements}

\subsubsection{Measurement of the early-age shrinkage of con- crete under sealed condition (before $1 \mathrm{~d}$ )}

Early age testing in the slab arrangement began approximately $30 \mathrm{~min}$ after water addition to the concrete mixing process. The fresh concrete was placed in the $100 \times 100 \times$ $515 \mathrm{~mm}$ steel mold and consolidated by an exterior vibrating table. An automatically measuring system ${ }^{10)}$ is developed by the incorporation of non-contact sensor for the deformation behavior of the early-age concrete including the settlement shrinkage from the casting and the self-desiccation shrinkage from the initial setting (as seen in Fig. 2). The equipment is usually used to measure the shrinkage of concrete at the age of initial 24 hours, and is assembled as two separate molds to simultaneously evaluate settlement and self-desiccation shrinkage.

\subsubsection{Measurement of the long-term shrinkage of hard-} ed concrete

One batch of concrete specimens for measuring long-term shrinkage of concrete was casted in the $100 \times 100 \times 515 \mathrm{~mm}$

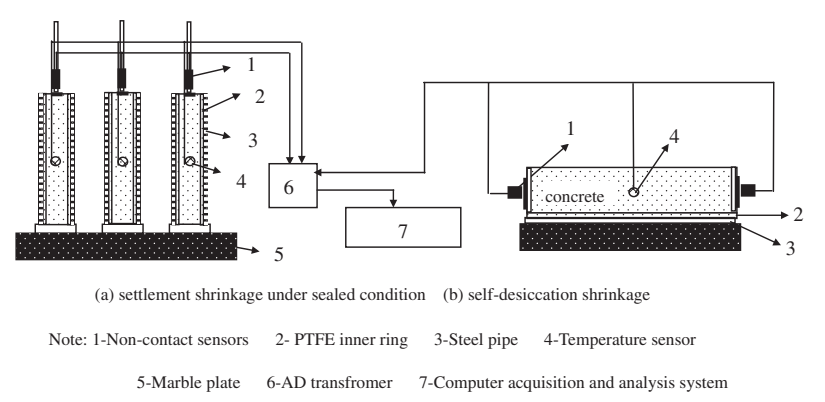

Fig. 2 Measuring systems of autogenous shrinkage for early-age concrete.

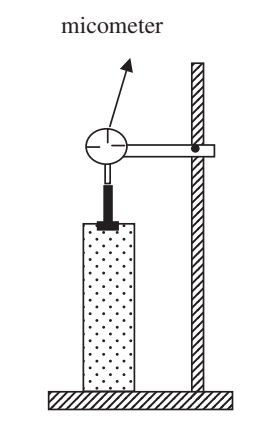

(a) Measurement of drying shrinkage

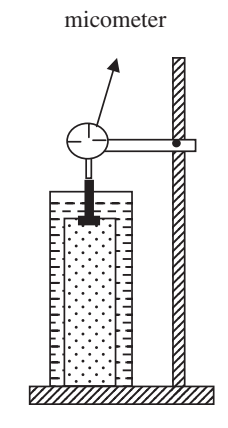

(b) Measurement of autogenous shrinkage after $1 \mathrm{~d}$
Fig. 3 Schematic of long-term shrinkage test arrangement.

prismatic steel moulds in accordance with GBJ82-85. After demolding, specimens were cured in a room at a constant temperature $\left(20 \pm 3^{\circ} \mathrm{C}\right)$ and a constant relative humidity level $(>90 \%)$ for 2 days. And then after initial reading, the specimens were exposed in a controlled room temperature of $20 \pm 2^{\circ} \mathrm{C}$ with a constant relative humidity level of $60 \pm 5 \%$. The length changes (see Fig. 3(a)) were monitored by micrometer at different time intervals up to 60 days.

Another batch of concrete specimens for measuring longterm autogenous shrinkage of concrete was casted in the $100 \times 100 \times 515 \mathrm{~mm}$ prismatic steel moulds with double inner polypropylene film. Immediately after casting, a layer of soft impermeable polypropylene film was covered on the surface of specimen. Just after demolding at the age of 1 day, the samples were first covered with a layer of liquid paraffin on six surfaces, and then placed in the $110 \times 110 \times 550 \mathrm{~mm}$ cuboids iron barrel, further the empty space is filled with liquid paraffin in order to avoid moisture exchange with the surroundings. After initial length measurement, specimens were exposed in the curing room maintained at $T=20 \pm$ $2{ }^{\circ} \mathrm{C}$ and a $\mathrm{RH}=60 \pm 5 \%$. The length changes were monitored by micrometer (see Fig. 3(b)) at different time intervals up to 60 days. The set-up and the test procedure are detailed in Ref. 10).

\subsection{Surface tension test}

The surface tension of different concentration of admixtures was measured at $25^{\circ} \mathrm{C}$ by a surface tension meter using a platinum plate. (Pure water as reference)

\subsection{Adsorption measurement}

The amount of adsorbed admixtures was calculated from the concentration of the admixture in the initial solution and 
Table 3 Effect of JM-PCA (IV) dosage on properties of freshly mixed concrete and compressive strength.

\begin{tabular}{|c|c|c|c|c|c|c|c|c|}
\hline \multirow[t]{2}{*}{ Admixtures } & \multirow{2}{*}{$\begin{array}{l}\text { Dosages } \\
(\mathrm{C} \times \%)\end{array}$} & \multirow[t]{2}{*}{$\mathrm{W} / \mathrm{C}$} & \multirow{2}{*}{$\begin{array}{c}\text { Water reduction } \\
\text { rate }(\%)\end{array}$} & \multicolumn{2}{|c|}{$\begin{array}{l}\text { Setting times } \\
\text { (h:min) }\end{array}$} & \multirow{2}{*}{$\begin{array}{c}\text { Air } \\
\text { content }(\%)\end{array}$} & \multicolumn{2}{|c|}{$\begin{array}{c}\text { Compressive } \\
\text { strengths }(\mathrm{MPa})\end{array}$} \\
\hline & & & & Initial & Final & & 28 days & 60 days \\
\hline \multirow{6}{*}{ JM-PCA (IV) } & - & 0.538 & - & $8: 45$ & $13: 55$ & 2.3 & $36.5 / 100$ & $41.7 / 100$ \\
\hline & 0.16 & 0.438 & 18.6 & $7: 55$ & $12: 20$ & 3.1 & $60.3 / 100$ & $64.8 / 155$ \\
\hline & 0.20 & 0.420 & 22.3 & $8: 15$ & $12: 45$ & 2.5 & $61.2 / 167$ & $66.2 / 159$ \\
\hline & 0.24 & 0.41 & 23.8 & $8: 20$ & $12: 50$ & 2.3 & $62.7 / 172$ & $67.3 / 161$ \\
\hline & 0.30 & 0.402 & 25.2 & $8: 35$ & $12: 35$ & 2.5 & $65.9 / 180$ & $69.2 / 166$ \\
\hline & 0.36 & 0.398 & 25.5 & $8: 10$ & $12: 30$ & 2.5 & $64.2 / 176$ & $67.8 / 163$ \\
\hline Might100 & 0.45 & 0.422 & 21.6 & $8: 35$ & $13: 35$ & 3.1 & $55.6 / 152$ & $57.3 / 137$ \\
\hline Might100+JM-SRA & $0.45+2.0$ & 0.413 & 23.2 & $9: 15$ & $13: 40$ & 4.9 & $50.5 / 138$ & $53.7 / 129$ \\
\hline
\end{tabular}

the liquid phase (after admixture adsorption). In the tests, $300 \mathrm{~g}$ cement and $135 \mathrm{~g}$ water containing the admixture are blended by mechanical stirring for 30 minutes. The liquid phase was obtained from the cement-admixture suspension by centrifugal separation with $13000 \mathrm{rpm}$ for 10 minutes. The admixture concentration was measured by carbon analysis using a Total Organic Carbon Analyzer (TOC).

\subsection{Porosity measurement}

Cement pastes were prepared with a water-to-cement $(\mathrm{W} / \mathrm{C})$ ratio of 0.29 by adding the tap water containing the defined amount of polymer dosages to the appropriate amount of cement. Each paste was blended by a machine controlled mixer for $3 \mathrm{~min}$, and placed in the $20 \times 20 \times$ $80 \mathrm{~mm}$ steel mold and consolidated by an exterior vibrating table. Just after demolding at the age of 1 day, specimens were cured in the standard curing room maintained at $T=$ $20 \pm 3$ and $\mathrm{RH}>90 \%$ for defined ages. The specimen fragments with different curing ages used for this investigation were taken from the core of specimens. Then they were immediately plunged in absolute acetone for $6 \mathrm{~h}$ to stop the hydration of cement and then dried at $105^{\circ} \mathrm{C}$ by using vacuum oven for $12 \mathrm{~h}$ before being tested. After drying, the porosity of fragments was performed by mercury intrusion porosimetry device made by Quantachrome Corporation.

\section{Results and Discussion}

\subsection{Properties of freshly mixed concrete and hardened concrete}

Concrete test results are shown in Table 3, the results indicate that with the increase of the dosages of JM-PCA (IV) in concrete, the water reduction increased. When $0.2 \%$ of JM-PCA (IV) was added, the water reduction was up to $22.3 \%$, as compared to the reference mix; while the water reduction at the dose of $0.30 \%$ was approximately $25.2 \%$. To obtain the same water reduction, the doasge of JM-PCA (IV) (dosage: $\mathrm{C} \times 0.2 \%$ ) is less the half of Might100 (dosage: $\mathrm{C} \times 0.45 \%)$. Generally, the setting of concrete is retarded and the strength of concrete is adversely influenced by including shrinkage reducing agent; However, JM-PCA (IV) containing shrinkage reducing component shows similar setting characteristics and strength development without retarding cement setting characteristics when compared with Might100.

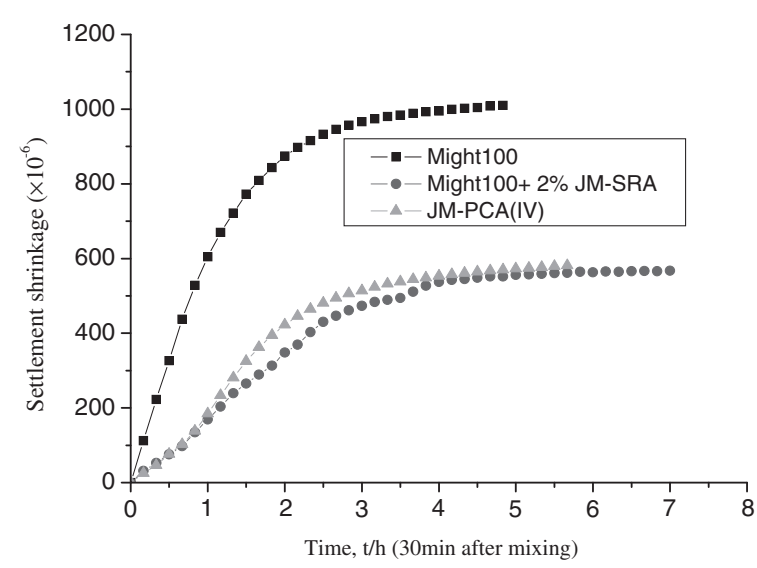

Fig. 4 Effect of admixture type on settlement shrinkage of concrete.

\subsection{Effect of admixture type on early-age shrinkage of concrete}

Figure 4 shows the effects of admixture type on settlement shrinkage. It is observed that JM-PCA (IV) decrease the settlement shrinkage effectively. The settlement shrinkages of concrete treated by JM-PCA (IV), Might100+JM-SRA and Might100 were $5.79 \times 10^{-4}, 5.67 \times 10^{-4}$ and $10.1 \times$ $10^{-4}$ respectively. The settlement shrinkage of concrete with $0.25 \%$ JM-PCA (IV) is only $57 \%$ of that of concrete with $0.74 \%$ Might 100 .

Figure 5 depicts the effects of admixture type on selfdesiccation shrinkage at 1 day. The data show a great reduction in self-desiccation shrinkage for the JM-PCA (IV) treated concrete. The self-desiccation shrinkages of concrete treated by JM-PCA (IV), Might100+JM-SRA and Might100 were $1.34 \times 10^{-4}, 1.27 \times 10^{-4}$ and $2.77 \times 10^{-4}$ respectively. $0.25 \%$ JM-PCA (IV) by weight of cement reduces the self-desiccation shrinkage by $51.6 \%$ compared with $0.74 \%$ Might 100 .

\subsection{Effect of admixture type on long-term shrinkage of harded concrete}

Figure 6 and Table 4 illustrate the effect of admixture type on long-term drying shrinkage. Compared with Might100 at a dosage $0.74 \%$, JM-PCA (IV) at dosage of $0.25 \%$ decreases the drying shrinkage by $41.7 \%$ at 28 days and by $41.9 \%$ at 60 days, respectively.

Figure 7 and Table 4 illustrate the effect of admixture type 


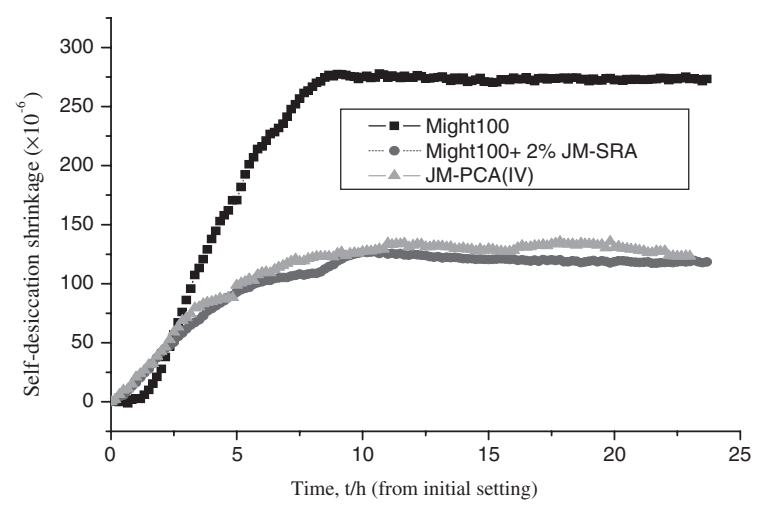

Fig. 5 Effect of admixture type on self-desiccation shrinkage of concrete at 1 day.

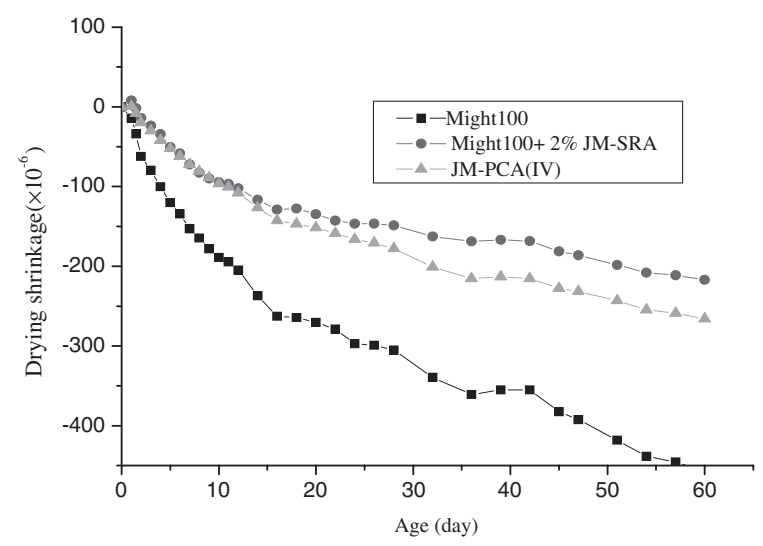

Fig. 6 Effect of admixture type on long-term drying shrinkage of concrete.

on long-term autogenous shrinkage. JM-PCA (IV) at a dosage of $0.25 \%$ decreases the autogenous shrinkage by $52.8 \%$ at 28 days and by $51.6 \%$ at 60 days compared with Might100 at a dosage of $0.74 \%$.

As can be seen from these results, by using JM-PCA (IV), the similar or the same shrinakge reduction result can be acquired as that of SRA. However, the additive amount of JM-PCA (IV) (dosage: $\mathrm{C} \times 0.25 \%$ ) is appearently less than the amount of JM-SRA (dosage: $\mathrm{C} \times 2.0 \%$ ). Also it shows high dispersion ability and does not retard setting characteristics of cement.

\subsection{Mechanism of the reduction of shrinkage}

The actual mechanism by which drying shrinkage occurs are complex. In order to explore the mechanism of the reduction of drying shrinkage, the surface tension, adsorption ratio of admixture to cement, porosity of harded cement paste treated by different admixtures were measured.

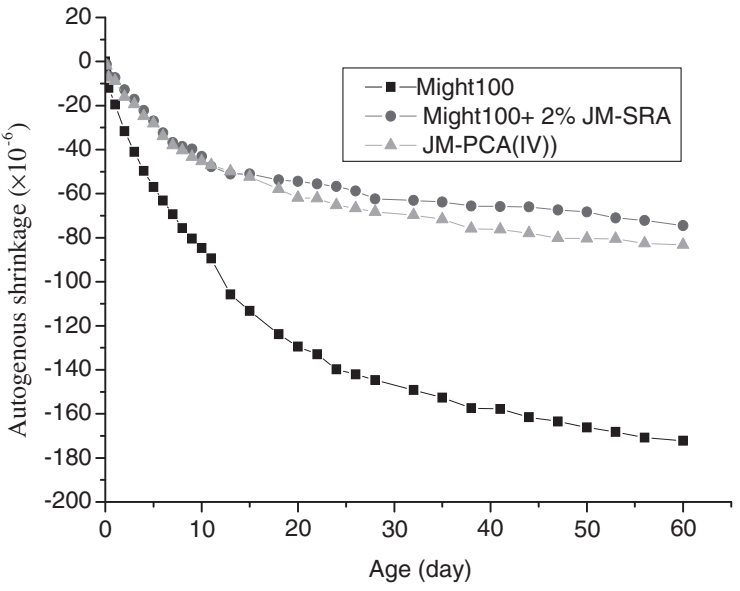

Fig. 7 Effect of admixture type on long-term autogenous shrinkage of concrete.

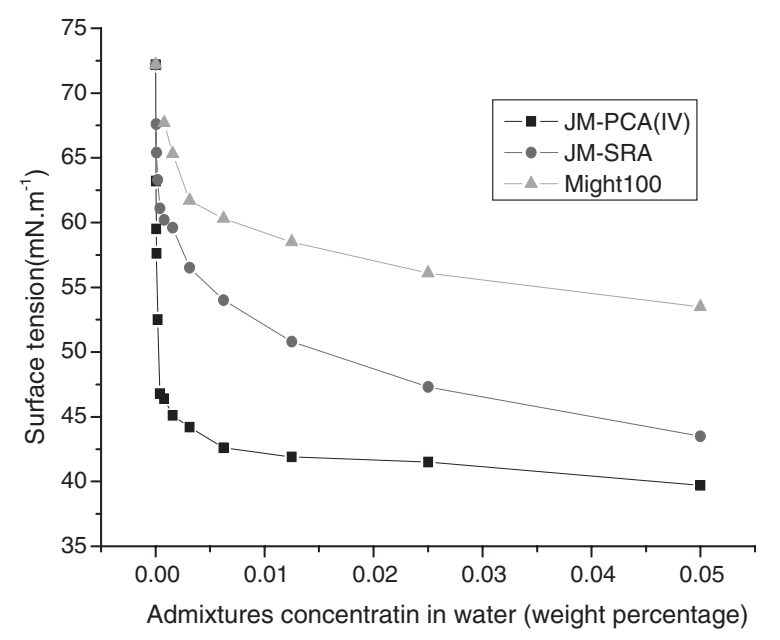

Fig. 8 Effect of different admixture concentration on surface tension.

In general, SRA reduce the shrinkage of concrete by reducing the surface tension of pore solution, the empty pore number which leads to lower capillary stresses during drying. Figure 8 shows the surface tension of admixture with different concentration. It can be observed that both JMSRA and multifunctional superplasticizer JM-PCA (IV) reduce the surface tension dramatically; However, the concentration of JM-SRA is quite higher than that JM-PCA (IV). The solution's surface tension of JM-SRA can exceed $50 \mathrm{Nm} \cdot \mathrm{m}^{-1}$ at weight concentration of $1.25 \%$; While the solution's surface tension of JM-PCA (IV) reaches the value lower than $50 \mathrm{Nm} \cdot \mathrm{m}^{-1}$ even at weight concentration of $0.02 \%$. The reduction of shrinkage seems to be related to the

Table 4 Test results of autogenous shrinkage and drying shrinkage of concrete.

\begin{tabular}{|c|c|c|c|c|c|c|c|c|c|}
\hline \multirow[t]{2}{*}{ Admixture } & \multirow{2}{*}{$\begin{array}{l}\text { Dosages } \\
(\mathrm{C} \times \%)\end{array}$} & \multirow[t]{2}{*}{ Slump $(\mathrm{cm})$} & \multirow{2}{*}{$\begin{array}{c}\text { Air } \\
\text { content }(\%)\end{array}$} & \multicolumn{2}{|c|}{$\begin{array}{c}\text { Compressive } \\
\text { strength (MPa) }\end{array}$} & \multicolumn{2}{|c|}{$\begin{array}{c}\text { Autogenous } \\
\text { shrinkage }\left(\times 10^{-6}\right)\end{array}$} & \multicolumn{2}{|c|}{$\begin{array}{l}\text { Drying shrinkage } \\
\qquad\left(\times 10^{-6}\right)\end{array}$} \\
\hline & & & & $7 d$ & $28 \mathrm{~d}$ & $28 \mathrm{~d}$ & $60 d$ & $28 \mathrm{~d}$ & $60 \mathrm{~d}$ \\
\hline Might100 & 0.74 & 18.0 & 2.3 & 66.5 & 74.6 & -144.679 & -172.189 & -305.02 & -457.423 \\
\hline Might100+JM-SRA & $0.74+2.0$ & 19.0 & 4.5 & 49.7 & 63.6 & -62.3996 & -74.4257 & -148.795 & -216.946 \\
\hline
\end{tabular}




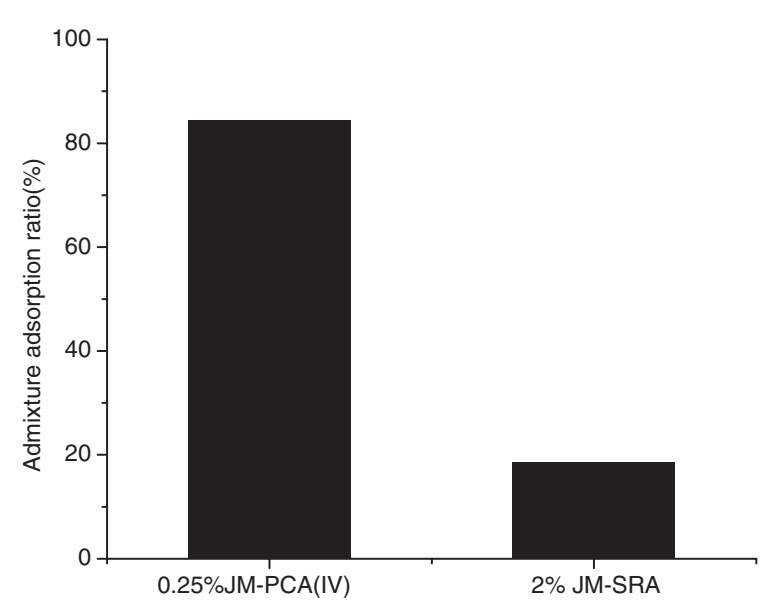

Fig. 9 Admixture type and adsorption to cement.

admixture dosage. It seemed that the minum dosage of JMSRA is about $1.5 \%$ by weight of cement as its shrinakge effect take place effectively. However from Figure 8, it can be seen tha JM-PCA (IV) is very effective to reduce the shrinkage of concrete even at a much lower rate than $0.25 \%$. This dosage difference between JM-SRA and JM-PCA (IV) maybe due to their different affinity towards the surface of cement particles or cement hydration products, which result in significant difference of adsorption of admixture to cement as shown in Fig. 9 for two types of admixture. JM-SRA mostly exists in solution phase due to its weak adsorption capability; While JM-PCA (IV) bearing charged groups (e.g. $\left.\mathrm{COO}^{-}\right)$is adsorbed strongly to the cement particles or cement hydration products. Thus most multi-functional superplasticizer molecules exist at cement-solution interface which helps to lower the interface tension more efficiently. These characteristics of JM-PCA (IV) make it reach higher reduction of shrinkage at low dosage. In the real hydration mix, the concentration of admixture in the pore solution is likely to reach a higher value with the progress of hydration than the initial concentration. In addition, the SRC concentration in pore solution also increases mainly due to the release of SRC from JM-PCA (IV) by debonding from site of ester group. Although the mechanism of drying shrinkage are not fully understood, for a given pore structure, the surface tension of pore water solution is proportional to the effect of admixture to reduce drying shrinkage of concrete. ${ }^{11)}$

Generally, the incorporation of chemical admixtures is known to affect both the total porosity and the pore size distribution of hardened cement paste, and the internal pore spaces influences the shrinkage of concrete. ${ }^{12)}$ Complementary porosity analyses are being done to helt to understand the effect of the multi-functional superplasticizer on concrete pore structure and its action mechanism. Pore size distributions of hardened cement paste containing different admixtures at different ages are illustrated in Fig. 10.

It is shown that the pore distribution of cement paste treated by JM-PCA (IV) after only 3 days becomes coarser than containing Might100. For JM-PCA (IV), a main broad peak at about $53 \mathrm{~nm}$ is observed. Some macroscopic pores peaks between $200 \mathrm{~nm}$ and $1 \mu \mathrm{m}$ can be observed. And the percentage of those $50 \mathrm{~nm}$ or larger pores increases. After 28

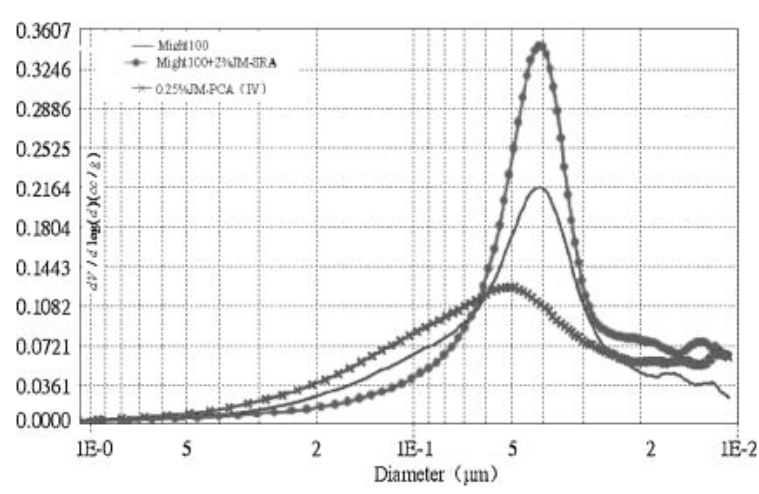

(a) after 3days

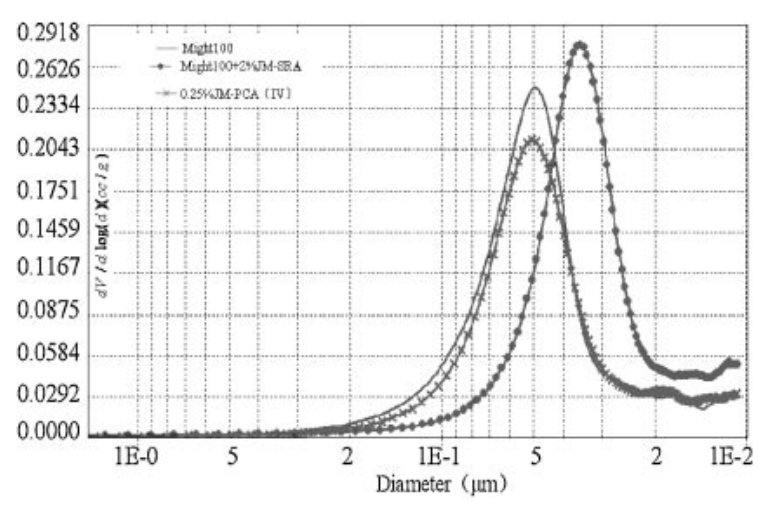

(b) after28days

Fig. 10 Pore size differential distribution of hardened cement paste treated by different admixture.

days, it is observed a displacement of this peak towards the pores of about $50 \mathrm{~nm}$ diameter. The porosity relative to the pores between 50 to $100 \mathrm{~nm}$ in diameter was $27.77 \%$ at the age of 3 days, and $50.34 \%$ at the age of 28 days. The total porosity was $21.1 \%$ at the age of 3 days, and $18.6 \%$ at the age of 28 days. Therefore, the hardened cement paste treated by JM-PCA (IV) has a denser microstructure but a broader porosity distribution.

According to Young-Laplace equation and Kelvin equation, as the diameter of capillary decrease, the capillary under-pressure increases and the internal relative humidity drops quickly which will in-turn induces stress and shrinkage. Therefore, the pore distribution of cement paste treated by JM-PCA (IV) becomes broader will also help to reduction of shrinkage.

Based on the surface tension, adsorption capability and porosity analyses, It can be conclude that the adsorptionreduction of interface tension and the coarser pore distribution are the main mechanism of a multifunctional superplasticizer to reduce the shrinkage of concrete.

\section{Conclusions}

Performance and the working mechanism of a new of superplasticizer with a high water-reduction performance and a good shrinkage reduction effect were investigated.

(1) The effectiveness of water reduction by a multifunction superplasticizer in concrete is very good. The water reduction can reach up to $22.3 \%$ at a rate of $0.20 \%$ by 
weight of cement; When $0.30 \%$ was added, $25.2 \%$ water reduction can be obtained. Moreover, the setting and strength characteristics of the multifunction superplasticizer are quite acceptable.

(2) The settle shrinkage and self-desiccation shrinkage of concrete at 1 day containing multifunction superplasticizer was effectively reduced by $43 \%$ and $51.6 \%$, respectively, compared with sulfonated naphthalene formaldehyde condensate superplasticizer; In contrast, a conventional organic shrinkage reducing admixture showed $43.9 \%$ and $54 \%$ reduction with eight times higher dosage, respectively.

(3) Compared with Might100 at a dosage 0.74\%, JM-PCA (IV) at dosage of $0.25 \%$ decreases the autogenous shrinkage of concrete by $52.8 \%$ at 28 days and by $51.6 \%$ at 60 days, respectively. And also reduces the drying shrinkage of concrete by $41.7 \%$ at 28 days and by $41.9 \%$ at 60 days, respectively.

(4) The adsorption-reduction of interface tension and the coarser pore distribution are the main mechanism of a multifunctional superplasticizer to reduce the shrinkage of concrete.

\section{Acknowledgments}

This study was supported by the Jiangsu Provincial Government under Grant No. BM2003516. and is part of a project funded by the innovation fund for small technologybased firms (Contract No. 02C6213210067). We want to thank our colleagues, J. Zhou and R. Mu for their help in producing the polymer and valuable comments in carrying out the experiments.

\section{REFERENCES}

1) D. P. Bentz, M. R. Geiker and K. K. Hansen: Cem Concr Res. 31 (2001) 1075-1085.

2) F. M. Lea: The Chemistry of Cement and Concrete, third edition, (Edward Arnold Publishers, London, 1976) pp. 533-536.

3) Y. S. Xu and D. D. L. Chung: Cem Concr Res. 30 (2000) 241-245.

4) C. K. Nmai, R. Romita, F. Hondo and J. Buffenbarger: Concr. Int. 4 (1998) 31-37.

5) S. Nagataki and H. Gomi: Cement \& Concrete Composites. 20 (1998) $163-170$.

6) M. Collepardi, A. Borsoi and S. Collepardi, et al.: Cement \& Concrete Composites. 27 (2005) 704-708.

7) J. Engstrand: Con. Chem. J. 4 (1997) 149-151.

8) T. Sugiyama, A. Ohta and Y. Tanaka: $4^{\text {th }}$ CANMEMT/ACI/JCI International Symposium on Advances in Concrete Technology, ed. by V. M. Malhotra, (ACI, SP-179, 1998) pp. 189-200.

9) H. Nakanishi, S. Tamaki, M. Yaguchi, K. Yamada, M. Kinoshita, M. Ishimori and S. Okazawa: $7^{\text {th }}$ CANMENT/ACI International Conference on Superplasticizers and Other Chemical Admixtures in Concrete, ed. by V. M. Malhotra, (ACI, SP217, 2003) pp. 327-341.

10) Q. Tian, W. Sun, C. W. Miao and J. P. Liu: J. Building Materials. 8 (2005) 82-89.

11) R. Rixom and N. Mailvaganam: Chemical Admixtures for Concrete, (E. \& F. N. Spon, London, 1999) pp. 265-267.

12) A. I. Hua and J. Francis Young: Proceedings of the 10th International Conference on the Chemistry of Cement, (vol. 3, Gfteborg, Sweden, 1997) pp. 18-22. 